\title{
Influence of Different Preparation Methods of Copper Loading on Na-Y Zeolite for Green Gas Emission
}

\author{
Patcharin Worathanakul and Nattachar Rakpasert
}

\begin{abstract}
This research was focused on different preparation methods of copper loading on zeolite. Cu cation supported on $\mathrm{Na}-\mathrm{Y}$ zeolite $(\mathrm{Cu}-\mathrm{Y})$ was prepared by aqueous solution ion exchange and incipient wetness impregnation methods. Different amounts of copper (II) were loaded in the $\mathrm{Na}-\mathrm{Y}$ zeolite. The catalysis materials were characterized by X-ray diffraction, X-ray fluorescence and Brunauer-Emmett-Teller. The results show that $\mathrm{Cu}$ loading did not change the structure of $\mathrm{Na}-\mathrm{Y}$ zeolite. The obtained $\mathrm{Cu} / \mathrm{Y}$ has enlarged pore size and octahedral shaped crystal with approximately $0.19 \pm 0.08 \mu \mathrm{m}$ diameter. $5.5 \mathrm{wt}$. $\% \mathrm{Cu} / \mathrm{Y}$ with impregnation method clearly exhibits a higher BET surface area and a total pore volume than $5.5 \mathrm{wt}$. \% solution ion exchanged.
\end{abstract}

Index Terms-Na-Y zeolite, green gas emission, X-ray powder diffraction, scanning electron microscope (SEM).

\section{INTRODUCTION}

The FAU-type zeolites, including FAU-X and FAU-Y, with a 3-dimensional pore structure have large channels, large surface area, high cation exchange capacity, high activity, possession of a highly catalytic center and high surface energy [1]. It has been found that the size of zeolite crystals could be a significant impact on the catalytic performance [2]. FAU-Y can be used for large molecules separating and it is also reported that FAU-Y with small particle size can improve catalytic cracking selectivity, reduce coke formation, increase the yield of diesel oil, faster diffusion and higher external surface area as well as easier cation exchange and template extraction, etc. [3], [4].

To reduce the greenhouse effect, caused by a substantial rise in $\mathrm{CO}_{2}$ concentration in the atmosphere, the development of technologies for fixing and recycling $\mathrm{CO}_{2}$ emissions is required [5], [6]. Crystalline microporous materials like zeolite have been found important industrial applications in processes such as catalysis, molecular sieving, gas separation and ion exchange. The major classes of microporous materials are represented by zeolites such as MOR, FAU and ZSM-5 [7]. Zeolite are said to have some advantages such as enrichment of reactants in a zeolite pore, ion-exchange ability, high dispersion of loaded metals and, thus, control of valence

Manuscript received March 9, 2016; revised May 17, 2016.

Patcharin Worathanakul is with the Department of Chemical Engineering, Faculty of Engineering, King Mongkut's University of Technology North Bangkok, 10800, Thailand. She is also with Center of Eco-material and Cleaner Technology, King Mongkut's University of Technology North Bangkok, 10800, Thailand (e-mail: patcharin.w@eng.kmutnb.ac.th).

Nattachar Rakpasert is with the Department of Chemical Engineering, Faculty of Engineering, King Mongkut's University of Technology North Bangkok, 10800, Thailand (e-mail: patcharin_wr@yahoo.com). of the metals [8]. The sizes of intra-crystalline channel/pore and guest molecule are often one of the key parameters in zeolite diffusivity. Many researchers have reported that zeolite diffusivity can be correlated with the critical diameter of guest molecule [9].

FAU-Y or Na-Y zeolite can be also used for many applications such as pervaporation for dehydration, vapor permeation for organic/organic separation, gas separation such as $\mathrm{CO}_{2} / \mathrm{N}_{2}$ and $\mathrm{NO}$ reduction [10]-[19]. Different preparation methods have been utilized for the preparation of transition metal on zeolite support as conventional ion exchange in aqueous solution, solid-state ion-exchange, sublimation or chemical vapour deposition, the ex-framework and impregnation method. Ramirez and his co-workers [20] reported that the Fe-MFI prepared by ex-framework is more active towards direct $\mathrm{N}_{2} \mathrm{O}$ decomposition than that obtained via SSIE methods. Li and his co-workers [21] reported that the $\mathrm{Cu}-\mathrm{TS}-1 /$ cordierite prepared with two methods as ion-exchange and impregnation exhibited similar high activities, the max $\mathrm{NO}_{\mathrm{x}}$ conversion at $58 \%$. Liu and his co-workers [22] reported that $\mathrm{Cu} / \mathrm{MCM}-41$ for selective catalytic $\mathrm{NO}$ reduction with $\mathrm{NH}_{3}$ prepared from the templateand hydroxyl group-ion exchanges show high activities at low $\mathrm{Cu}$ contents, while a high $\mathrm{Cu}$ content was required for the impregnation method to reach a high activity. Moreover, the template-ion exchange was found to have the advantage in maintaining the physical of the support. The aim of this paper was to compare preparation methods of $\mathrm{Cu}$ (II) loading on $\mathrm{Na}-\mathrm{Y}$ zeolite supported by aqueous solution ion exchange and incipient wetness impregnation methods. The obtained samples will with different metal loadings to further reduction of $\mathrm{CO}_{2}$ and oxides of nitrogen.

\section{MATERIALS AND METHODS}

The material used for synthesize of $\mathrm{Na}-\mathrm{Y}$ zeolite are as follow: Sodium hydroxide $(\mathrm{NaOH} 99 \mathrm{wt} \%$, Merck) for sodium source, Sodium aluminate $\left(\mathrm{Al}_{2} \mathrm{O}_{3} 50-56 \%\right.$ wt., $\mathrm{Fe}_{2} \mathrm{O}_{3}$ 0.05 wt \%., $\mathrm{Na}_{2} \mathrm{O} 40-45$ wt. \%, Aldrich) for alumina source and Sodium silicate $\left(\mathrm{Na}_{2} \mathrm{O} 18 \%\right.$ wt., $\mathrm{SiO}_{2} 63 \%$ wt., Aldrich) for silica source and Copper (II) nitrate trihydrate $\left(\mathrm{Cu}\left(\mathrm{NO}_{3}\right)_{2} \cdot 3 \mathrm{H}_{2} \mathrm{O} 98 \%\right.$ wt., Merck) for $\mathrm{Cu}$ loading.

\section{A. Na-Y Synthesis}

$\mathrm{Na}-\mathrm{Y}$ zeolite was prepared at $\mathrm{Si} / \mathrm{Al}$ ratio 0.75 and divided into seed gel, feedstock gel and overall gel.

\section{1) Seed gel}

The preparation of seed gel comprises of $5 \%$ of the whole gel. Sodium silicate solution (S1) was prepared by mixed sodium hydroxide, distilled water and sodium silicate with 
stirring until dissolved. Sodium aluminate solution (S2) was prepared by mixed sodium hydroxide, distilled water and sodium aluminate stirring until dissolved. Then, sodium aluminate solution and sodium silicate solution were mixed together by stirring moderately and left at ambient temperature for $24 \mathrm{~h}$. The mixed solution was called seed gel.

\section{2) Feed stock gel}

The preparation of feedstock gel comprises of $95 \%$ of the whole gel. The methodology is similar to the preparation of seed gel but large quantity of starting material. Then, sodium silicate solution (F1) and sodium aluminate solution (F2) were mixed together by stirring vigorously and left at ambient temperature for 1 night. The mixed solution was called feed stock gel.

\section{3) Overall gel}

The feedstock gel and seed gel were mixed as overall gel. The feedstock gel was started with stirring left them at ambient temperature for 1 night. After $5 \mathrm{~h}$, the gel was settled to the solid at the bottom, and a hazy supernatant liquid to the top. The samples were continued heated at $100{ }^{\circ} \mathrm{C}$ until the supernatant is clear. It should not be exceed $2 \mathrm{~h}$ addition with complete crystallization. After that, the samples were aged at room temperature for 1 night and heat was added in crystallization step. The overall gel was filtered with distilled water until $\mathrm{pH}$ of filtrate is below 9 and dried at $110{ }^{\circ} \mathrm{C}$ overnight. The synthesized conditions were performed

\section{B. Difference Copper Loading Methods}

\section{1) Incipient wetness impregnation of $\mathrm{Na}-\mathrm{Y}$ zeolite}

Copper (II) exchanged Na-Y zeolites ( $\mathrm{Cu} / \mathrm{Y}$-IM) were prepared with different percentages of $\mathrm{Cu}$ loading (2.3 wt. \% and $5.5 \mathrm{wt}$. \% by an incipient wetness impregnation method. It is necessary to keep the zeolite carrier completely wetted. Aqueous solution of metal-nitrate was added dropwise to the zeolite with continuous stirring. Finally, the zeolite was filtered and then dried at $120{ }^{\circ} \mathrm{C}$ overnight and calcined for 5 $\mathrm{h}$ at $600{ }^{\circ} \mathrm{C}$ in dry air.

\section{2) Aqueous solution ion exchanged $\mathrm{Na}-\mathrm{Y}$ zeolite}

For an aqueous solution ion exchange method, the metal-nitrate aqueous solution with a solid-to-liquid ratio of 1 $\mathrm{g} / 100 \mathrm{ml}$ was carried out under vigorous stirring at room temperature for $24 \mathrm{~h}$. The zeolite was filtered and dried at 120 ${ }^{0} \mathrm{C}$ overnight and calcined for $5 \mathrm{~h}$ at $600{ }^{\circ} \mathrm{C}$ in dry air. The exchanged samples as $\mathrm{Cu} / \mathrm{Y}$-IE were prepared at 2.3 wt. \% and $5.5 \mathrm{wt} \% \mathrm{Cu}$ loadings.

\section{Physicochemical Characterization}

The crystallinity of synthesized catalysts as $\mathrm{Cu}$ (II) on $\mathrm{Na}-\mathrm{Y}$ zeolites were analyzed following:

\section{1) X-ray powder diffraction $(X R D)$}

(XRD) patterns using X-ray powder diffraction (Phillips PW 1830/40, Netherlands) with $\mathrm{CuK}_{\alpha} 1$ radiation ( $\lambda=$ $1.5406 \mathrm{~A}^{\circ}$ ), generator tension $40 \mathrm{kV}$ and generator current 30 $\mathrm{mV}$.

\section{2) Scanning electron microscope (SEM)}

The crystal morphology and size of the obtained zeolite were determined via scanning electron microscopy (SEM) in the range of $5-70^{\circ}(2 \theta)$. The sample was coated with a thin layer of gold using a sputter coater (Edwards Laboratories, Milpitas, CA) before scanning electron microscope (SEM).

\section{3) BET N2-adsorption/desorption isotherm}

Specific surface area, adsorption/desorption isotherms, pore size and pore size distribution of the prepared samples were determined using BET- $\mathrm{N}_{2}$ adsorption (Quantachrome, Autosorb®-1-C) with microporous analysis (74 points $\mathrm{N}_{2}$ adsorption/ desorption).

\section{Catalytic Activity Test Procedure}

$\mathrm{Cu} / \mathrm{FAU}$ catalysts for nitric oxide (NO) with $\mathrm{H}_{2}$ reducer was primary studied in a continuous flow system with a fixed bed stainless steel tube reactor containing $0.3 \mathrm{~g}$ of catalyst as shown the condition in Table I. The reaction gas, a mixture of $\mathrm{NO}, \mathrm{H}_{2}$ and $\mathrm{O}_{2}$ with $\mathrm{He}$ balance was fed to the catalyst. The total flow is $200 \mathrm{~cm}^{3} / \mathrm{min}$. Before the reaction was started, the catalysts were activated under helium flow at pre-treated temperature at $500{ }^{0} \mathrm{C}$ for $1 \mathrm{~h}$. The temperature was then adjusted to reaction temperature at $600{ }^{\circ} \mathrm{C}$. The outlet gas compositions were analyzed by combustion analyzer with measurement every $2 \mathrm{~min}$ for $1 \mathrm{~h}$.

TABLE I: LIST OF THE STUDY CATALYTIC ACTIVITY

\begin{tabular}{|l|l|}
\hline Metal loading & Copper (II) nitrate trihydrate \\
\hline Metals loading method & $5.5 \% \mathrm{Cu} / \mathrm{FAU}-\mathrm{IM}$ \\
& $5.5 \% \mathrm{Cu} / \mathrm{FAU}-\mathrm{IE}$ \\
\hline Pretreated temperature & $500^{\circ} \mathrm{C}$ \\
\hline Reaction temperature & $600^{\circ} \mathrm{C}$ \\
\hline
\end{tabular}

\section{RESULTS AND DISCUSSION}

XRD patterns of $\mathrm{Cu} / \mathrm{Y}$-IM and $\mathrm{Cu} / \mathrm{Y}$-IE are shown in Fig. 1 according to standard peak as shown $2 \theta$ at $6,10,15.8,20.2$, 23.5, 27 and $31.3[19]$ and $\mathrm{Cu} / \mathrm{Y}$ shown $\mathrm{CuO}$ peaks at $2 \theta=$ $35.5,38.6,58.3$.

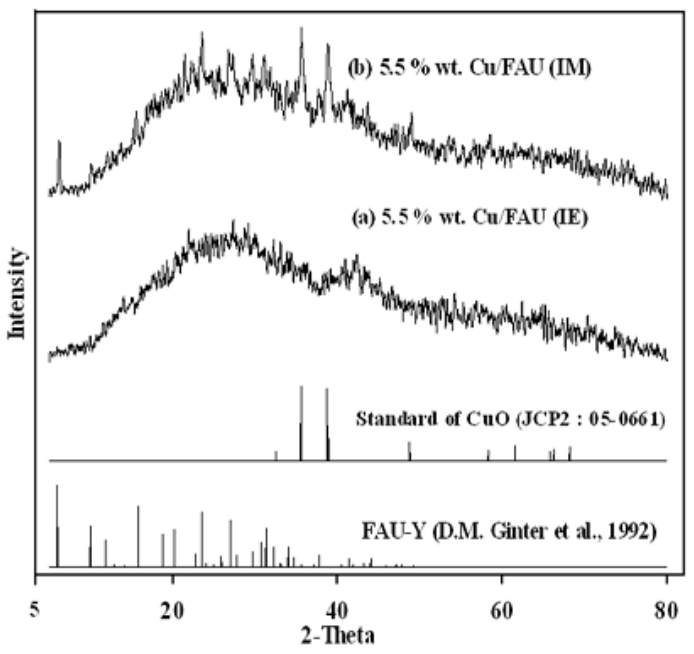

Fig. 1. XRD pattern of $\mathrm{Cu} / \mathrm{FAU}$.

This paper was shown only the results of $5.5 \mathrm{wt} \%$ loading on FAU zeolite since $2.3 \mathrm{wt} \%$ copper loaing has been revealed the similar trends results. In addition, ion exchange level was found under-exchanged (ion exchange level < 100\%) 
at $36.8 \%$ and $33.0 \%$ for $\mathrm{Cu} / \mathrm{Y}$-IM and $\mathrm{Cu} / \mathrm{Y}$-IM, respectively.

The pore size distribution shows diameter of both exhibit micropore $(<2 \mathrm{~nm})$ as shown in Fig. 2. The results reveal that it is potentially suitable uses for gas adsorption for environmental application.

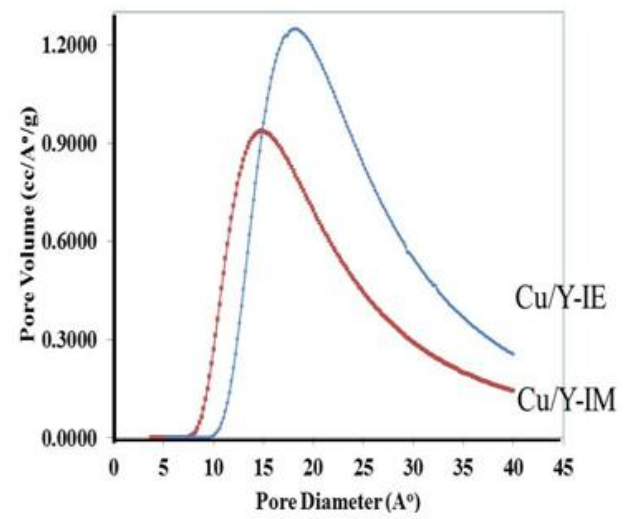

Fig. 2. Pore size distribution of $\mathrm{Cu} / \mathrm{Y}-\mathrm{IM}$ and $\mathrm{Cu} / \mathrm{Y}$-IE.

Specific surface area, pore volume and pore diameter of $\mathrm{Cu} / \mathrm{Y}$ zeolites with different preparation methods were characterized by BET $\mathrm{N}_{2}$-adsorption/desorption isotherms as shown in Table II. The results were shown that impregnation method with 5.5 wt. \% Cu loading clearly exhibits a higher BET surface area and a total pore volume than $5.5 \mathrm{wt} . \% \mathrm{Cu}$ loading with ion-exchanged method. The result can imply that higher BET surface area and high pore volume may reduce greenhouse gas emission for future application.

TABLE II: BET SURFACE AREA AND PORE VOLUME OF CATALYSTS

\begin{tabular}{|c|c|c|}
\hline \multirow[t]{3}{*}{ Physical properties } & \multicolumn{2}{|c|}{ Metals loading (wt.\%) } \\
\hline & $5.5 \%$ & $5.5 \%$ \\
\hline & $\mathrm{Cu} / \mathrm{FAU}-\mathrm{IM}$ & $\mathrm{Cu} / \mathrm{FAU}-\mathrm{IE}$ \\
\hline BET surface area ${ }^{2}\left(\mathrm{~m}^{2} / \mathrm{g}\right)$ & 114.1 & 52.3 \\
\hline Micropore volume ${ }^{1}\left(\mathrm{~cm}^{3} / \mathrm{g}\right)$ & 0.014 & 0.010 \\
\hline Total pore volume ${ }^{2}\left(\mathrm{~cm}^{3} / \mathrm{g}\right)$ & 0.235 & 0.204 \\
\hline Pore diameter ${ }^{3}(\AA)$ & 14.8 & 18.2 \\
\hline
\end{tabular}

t-plot micropore analysis method, ${ }^{2} \mathrm{MP}$ micropore analysis method at $\mathrm{P} / \mathrm{P}_{0}$ close to unity, ${ }^{3} \mathrm{DA}$ method micropore analysis
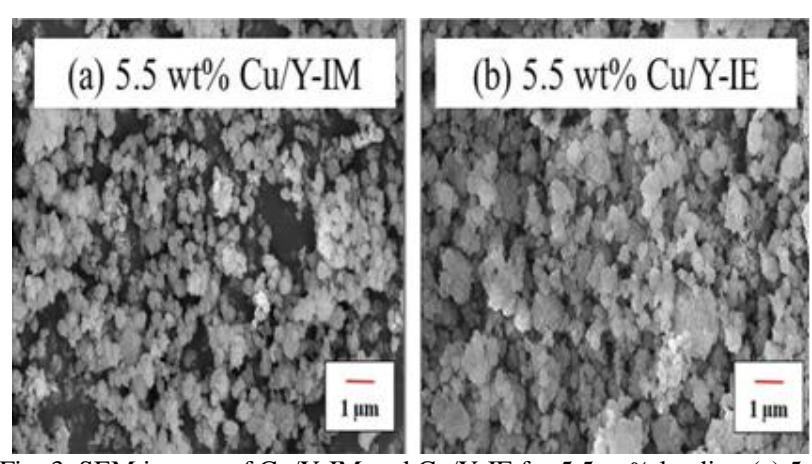

Fig. 3. SEM images of $\mathrm{Cu} / \mathrm{Y}-\mathrm{IM}$ and $\mathrm{Cu} / \mathrm{Y}$-IE for $5.5 \mathrm{wt} \%$ loading (a) 5.5 wt $\% \mathrm{Cu} / \mathrm{Y}-\mathrm{IM}$ and (b) $5.5 \mathrm{wt} \% \mathrm{Cu} / \mathrm{Y}$-IE.

Moreover, SEM images of $\mathrm{Cu} / \mathrm{Y}$-IM with incipient wetness impregnation exhibit that most of the octahedral shaped crystals, confirming the formation of $\mathrm{Y}$ zeolites (Fig. 3).
Metal loading did not change the Y-zeolite structure. It was also found that $\mathrm{Cu} / \mathrm{Y}$ crystals were approximately $0.19 \pm 0.08$ $\mu \mathrm{m}$ in diameter.

The catalysts from $5.5 \% \mathrm{Cu}$ loading prepared by incipient wetness impregnation method were shown higher nitric oxide conversion than aqueous solution ion exchange method (Table III) at reaction temperature of $600{ }^{\circ} \mathrm{C}$.

TABLE III: SUMMARIZE FOR NO CONVERSION OF 5.5 WT.\% CU CATALYSTS

\begin{tabular}{|c|c|}
\hline Type of catalysts & Nitric conversion (\%) \\
\hline 5.5 wt. $\% \mathrm{Cu} / \mathrm{Y}-\mathrm{IM}$ & 38.86 \\
\hline $5.5 \mathrm{wt} . \% \mathrm{Cu} / \mathrm{Y}-\mathrm{IE}$ & 32.67 \\
\hline
\end{tabular}

\section{CONCLUSIONS}

Different preparation methods of wet impregnation and ion exchanged have effect for various environmental applications such as nitric oxide reduction or carbon dioxide reduction. $\mathrm{Cu}$ loading on $\mathrm{Na}-\mathrm{Y}$ zeolite did not change the structure of $\mathrm{Cu}-\mathrm{Y}$ zeolite. The results can confirm that we can synthesize $\mathrm{Na}-\mathrm{Y}$ zeolite and metal loading on zeolites successfully. The obtained zeolite can further study more about catalytic testing in the future.

\section{ACKNOWLEDGMENT}

Authors would like to thank the research funding. This research was funded by King Mongkut's University of Technology North Bangkok, Contract no.KMUTNB-GEN-59-06.

\section{REFERENCES}

[1] N. Patdhanagul, T. Srithanratana, K. Rangsriwatananon, and S. Hengrasmee, Microporous and Mesoporous Materials, vol. 131, 2010, pp. 97-102.

[2] S. Sang, Z. Liu, P. Tian, Z. Liu, L. Qu, and Y. Zhang, Matarials Letters, vol. 60, 2006, pp. 1131-1133.

[3] H. J. Koroglu, A. Sarioglan, M. Tather, A. E. Senatalar, and O. T. Savasci, Journal of Crystal Growth, vol. 241, 2002, pp. 481-488.

[4] W. Bo and M. Hongzhu, Microporous and Mesoporous Materials, vol. 25, 1998, pp. 131-136.

[5] H. H. Khoo and R. B. H. Tan, Sci. Technol., vol. 40, 2006, pp. 4016-4024.

[6] A. Hansson and M. Bryngelsson, Energ. Policy, vol. 37, 2009, pp. 2273-2282.

[7] L. Gomez-Hortiguela, F. Cora, and J. Perez-Pariente, Microporous and Mesoporous Materials, vol. 109, 2008, pp. 494-504.

[8] A. Shichi, A. Satsuma, M. Iwase, K. I. Shimizu, S. I. Komai, and T. Hattori, Applied Catalysis B: Envonmental, vol. 17, 1998, pp. 107-113.

[9] A. Shichi, A. Satsuma, and T. Hattori, Applied Catalysis B: Envonmental, vol. 30, 2001, pp. 25-33.

[10] K. Backman, J. Jensen, F. Klingstedt, T. Salmi, and D. Y. Murzin, Applied Catalysis A: General, vol. 294, 2005, pp. 49-58.

[11] A. Sierraalta, A. Bermudez, and M. R. Brussin, Journal of Molecular Catalysis A: Chemical, vol. 228, 2005, pp. 203-210.

[12] B. I. Mosqueda-Jimenez, A. Jentys, K. Seshan, and J. A. Lercher, Journal of Catalysis, vol. 218, 2003, pp. 348-353.

[13] H. Yahiro and M. Iwamoto, Applied Catalysis A: General, vol. 222, 2001, pp. 163-181.

[14] A. D. Lucas, J. L. Valverde, F. Dorado, A. Romero, and I Asencio, Journal of Molecular Catalysis A: Chemical, vol. 225, 2005, pp. 47-58.

[15] I. O. Y. Liu and N. W. Cant, Journal of Catalysis, vol. 230, 2005, pp. 123-132.

[16] J. H. Kwak, J. Szanyi, and C. H. F. Peden, Catalysis Today, vol. 89, 2004, pp. 135-141. 
[17] K. Sato, K. Sugimoto, Y. Sekine, M. Takada, M. Matsukata, and T. Nakane, Microporous and Mesoporous Materials, vol. 101, 2007, pp. 312- 318.

[18] J. C. Yang and P. K. Dutta, Sensors and Actuators B, vol. 123, 2007, pp. $929-936$.

[19] D. M. Ginter, A. T. Bell, C. J. Radke, M. L. Occelli, H. E. Robson, Synthesis of Microporous Materials, Molecular Sieves, New York, 1992, p. 6.

[20] J. P. Ramirez, F. Kapteijn, G. Mul, and J. A. Moulijn, Applied Catalysis B: Environmental, vol. 35, 2002, pp. 227-234.

[21] L. Li, J. Chen, S. Zhang, N. Guan, T. Wang, and S. Liu, Catalysis Today, vol. 90, 2004, pp. 207-213.

[22] C. C. Liu and H. Teng, Applied Catalysis B: Environmental, vol. 58, 2005, pp. 69-77.

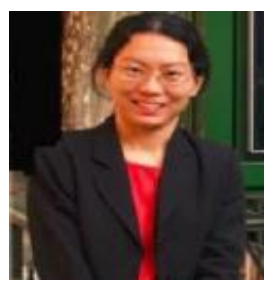

P. Worathanakul was born in Bangkok, Thailand on May 13, 1975. P. Worathanakul received a D.Eng. (chemical engineering) from the Kasetsart University, Bangkok, Thailand in 2008. P. Worathanakul did her doctoral research collaboration with Washington University in Saint Louis, USA during 2006-2007. P. Worathanakul received a M.S. (chemical engineering) and a B.S. (chemical engineering) from King Mongkut's University of Technology Thonburi in 1999 and Kasetsart University in 1997, Thailand, respectively.

She is now a faculty with an associate professor in the Department of Chemical Engineering, Faculty of Engineering, King Mongkut's University of Technology North Bangkok, Bangkok, Thailand. She had worked related to chemical, environmental and energy fields as a position of project manager/research associate at Thailand Environmental Institute during 1999-2004. She has published some papers in nanostructured composite materials synthesis and their applications. She is interested in catalytic properties of membrane for environmental and chemical applications as well as nanotechnology, advanced materials properties and cleaner technology.

Dr. Worathanakul became a member of American Chemical Society (ACS) in 2007 and Asia-Pacific Chemical, Biological\& Environmental Engineering Society (CBEES) in 2014. She is the member of International Association of Computer Science and Information Technology (IACSIT), the Council of Engineers and the Thai Institute of Chemical Engineering and Applied Chemistry. She has worked for carbon footprint committee in Thailand. She has recognized award for oral technical presentation at the 17th National Chemical Engineering and Applied Chemistry Conference and honor award advisor of Master's student year 2012.

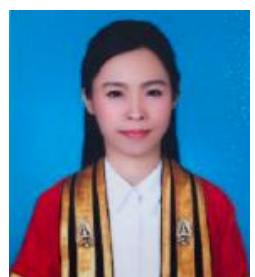

N. Rakpasert lives in Pathumthani province, Thailand. N. Rakpasert received a B.Sc.. (industrial chemistry) in 2009 and a M.S. (chemical engineering) in 2012 from the King Mongkut's University of Technology North Bangkok, Bangkok, Thailand. N. Rakpasert is now with the Intergrated Solutions Southeast Asia Co., Ltd. for procurement engineering position. 